\title{
A five-axis CNC machining method of orthogonal variable transmission ratio face gear
}

\author{
Chao LIN*, Yu FAN*, Yao WANG*, Xijun CAO* and Zhiqin CAI* \\ * The State Key Laboratory of Mechanical Transmission, Chongqing University 400044, Chongqing, China \\ E-mail: linchao@cqu.edu.cn
}

Received 11 July 2014

\begin{abstract}
In order to verify the validity of the design for the orthogonal variable transmission ratio face gear pair, a five-axis CNC machine tool was used to machine this gear. The cutter tooth profile coordinate system, orthogonal variable ratio face gear machining coordinates, the model for the round-corner at tooth tip, the contact line model and CNC machining models were established by using space gear meshing theory and the machining principle of five-axis CNC machine tools. The method of machining this gear along the contact line has been obtained through the combination of the envelope method and milling principle. Cutter tooth profile equations, coordinate transformation matrices between the non-circular gear tooth surface and orthogonal variable transmission ratio gear tooth surface, transition surface equations and five-axis motion equations were derived. The rolling experiment and tooth surface measurement experiment were conducted on the gear, which was processed by a five-axis CNC machine. The results show that the tooth surface accuracy of the orthogonal variable transmission ratio face gear is high. The design of the orthogonal variable transmission ratio face gear, and its processing method using a five-axis NC machine have been verified.
\end{abstract}

Key words : Face gear, CNC machining, Variable transmission ratio, Design, Drive

\section{Introduction}

Orthogonal variable transmission ratio face gear drive is a gear drive where a non-circular gear and an orthogonal variable ratio face gear are engaged with a 90 degrees' intersecting axis. The orthogonal variable transmission ratio face gear combines the features of non-cylindrical gear and bevel gear and it allows variable transmission ratio between intersecting axis. The driving wheel is an on-cylindrical gear, and the driven one is a face gear. The gear pair can realize given variable transmission ratio. The Orthogonal variable transmission ratio face gear pair is shown in Figure1. In this research report, OVTR face gear is stand for orthogonal variable transmission ratio face gear.

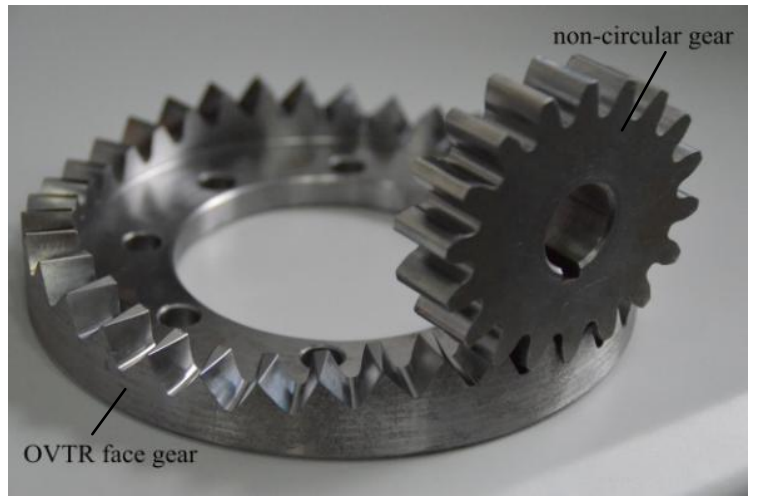

Fig. 1 OVTR face gear pair

In face gear drive, a cylindrical gear is engaged with a bevel gear (Litvin, et al., 1992). In 1940's, Buckingham introduced face gear in his book. Today, the face gear transmission structure is mainly used in the shunt transmission structure of the helicopter's main gear transmission system (George, 2002). Its narrow range of applications is attributed to reasons such as complexity of design, poor precision and difficulties in teeth grinding. The above reasons impeded 
the development and application of the face gear transmission.

DARPA in the U.S. investigated the face gear transmission technique in TRP project, with the aim to apply this technique to the new generation Apache helicopter gunship. The study included the manufacturing and experiment of carburized face gear. Saga University in Japan used a large helical hob with less gear to machine face gear (Ohshima, et al., 2009). U.S. Processing and Treatment Center improved the hob and made it possible to process small face gears and improve the accuracy of the tooth surface (Ishii, et al., 1992). Poznan University of Technology studied the milling method of face gears (Frackowiak, et al., 2012). Kyushu University in Japan studied the contact path of a face gear and improved the accuracy of assembly operation in mass production lines (Tetsuo and Syuhei, 2012). Some other scholars have also done a lot of research on face gear (Oshima, et al., 2006a, 2007b, 2007c, 2009d, Gunbara, 2007).

The research team of Litvin made great contribution to the research of the face gear. Litvin studied the geometric design of face gears. The main objects were face gear and helical face gear. The research included the machining, tooth surface generation, and the judging methods for tooth interference and sharp tip condition. Therefore the theory of point contact of face gear had been developed, which had a great significance for the practical application of face gears. In order to limit the transmission errors and reduce noise and vibration, Litvin accomplished the tooth surface modification and the point contact of face gear (Litvin, et al., 2002). Also, a new generation method of spiral in volute face gear had been proposed (Litvin, et al., 2005).

However, the transmission ratio of face gears is constant, this paper presents an orthogonal variable transmission ratio face gear, and transmission ratio can be defined to achieve variable ratio transmission. Compared with conventional face gears, which can be processed by slotting machine, the height of orthogonal variable transmission ratio face gears' tooth surface can be changed in the circumferential direction, which makes them difficult to process. This paper presents a machining method for orthogonal variable ratio face gears using a five-axis CNC machine tool in order to solve manufacturing problems of this new face gear, and also lay a solid foundation for further researches.

\section{Design of orthogonal variable transmission ratio face gear 2.1 Model of OVTR face gear tooth surface}

The cutter used for machining the OVTR face gear is an involute cylindrical gear, as shown in Figure2. $r_{\mathrm{b}}$ is the radius of the cutter, and $r_{\mathrm{bk}}$ is the basic circle of the cutter. $\theta_{\mathrm{ok}}$ is the cutter angle which is determined by the evolving angle, and $l_{e}$ is the tooth profile.

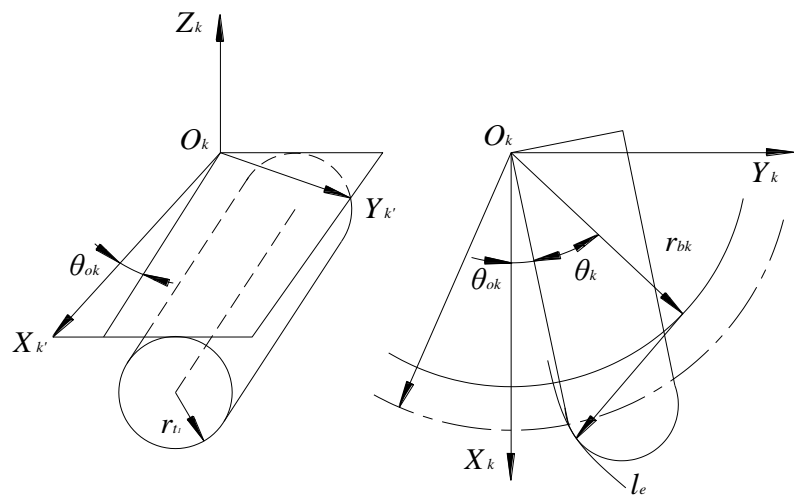

Fig. 2 Tooth profile of cutter

The tooth surface model of the face gear is enveloped by cutter using the generating method. So, the tooth profile equation of the cutter should be discussed firstly. The tooth profile of the cutter is symmetric, so one half tooth profile can be derived from the other half. The left tooth profile equation of cutter can be expressed as:

$$
\overrightarrow{r_{\mathrm{k}}}\left(u_{\mathrm{k}}, \theta_{\mathrm{k}}\right)=\left[\begin{array}{c}
r_{\mathrm{bk}}\left[\cos \left(\theta_{\mathrm{ok}}+\theta_{\mathrm{k}}\right)+\theta_{\mathrm{k}} \sin \left(\theta_{\mathrm{ok}}+\theta_{\mathrm{k}}\right)\right] \\
r_{\mathrm{bk}}\left[\sin \left(\theta_{\mathrm{ok}}+\theta_{\mathrm{k}}\right)-\theta_{\mathrm{k}} \cos \left(\theta_{\mathrm{ok}}+\theta_{\mathrm{k}}\right)\right] \\
u_{\mathrm{k}} \\
1
\end{array}\right]
$$

where $r_{\mathrm{bk}}=r_{\mathrm{k}} \cos \alpha_{\mathrm{u}}, \quad \alpha_{\mathrm{u}}$ is the pressure angle of the cutter, $\theta_{\mathrm{ok}}=\pi / 2 z_{\mathrm{k}}-i n v \alpha_{\mathrm{u}}$.

In order to describe the relationship between non-cylindrical gear and face gear, four coordinates $s\left(X_{s} Y_{s} Z_{s}\right)$, 
$s^{\prime}\left(X_{s^{\prime}} Y_{s^{\prime}} Z_{s^{\prime}}\right), f\left(X_{f} Y_{f} Z_{f}\right)$ and $f^{\prime}\left(X_{f^{\prime}} Y_{f^{\prime}} Z_{f^{\prime}}\right)$ were established based on the space engagement theory. Coordinate $s\left(X_{s} Y_{s} Z_{s}\right)$ is rigidly fixed on the frame of the non-cylindrical gear. Coordinate $s^{\prime}\left(X_{s^{\prime}} Y_{s^{\prime}} Z_{s^{\prime}}\right)$ is rigidly fixed on the non-cylindrical gear. Coordinate $f\left(X_{f} Y_{f} Z_{f}\right)$ is rigidly fixed on the frame of the face gear. Coordinate $f^{\prime}\left(X_{f^{\prime}} Y_{f}, Z_{f^{\prime}}\right)$ is rigidly fixed on the face gear. Coordinate $s\left(X_{s} Y_{s} Z_{s}\right)$ and coordinate $s^{\prime}\left(X_{s^{\prime}} Y_{s^{\prime}} Z_{s^{\prime}}\right)$ are over lapped at the initial time. Coordinate $s^{\prime}\left(X_{s^{\prime}} Y_{s^{\prime}} Z_{s^{\prime}}\right)$ rotates around axis $O_{s} Z_{s}$ with an angular velocity of $\theta_{1}$ in a clockwise direction. Coordinate $f\left(X_{f} Y_{f} Z_{f}\right)$ and coordinate $f^{\prime}\left(X_{f}, Y_{f}, Z_{f}\right)$ are over lapped at the initial time. Coordinate $f^{\prime}\left(X_{f^{\prime}} Y_{f^{\prime}} Z_{f^{\prime}}\right)$ rotates around axis $O_{f} Z_{f}$ with an angular velocity of $\theta_{2}$ in counter-clockwise direction. The distance between plane $X_{f} O_{f} Y_{f}$ and $X_{s} O_{s} Y_{s}$ is R, as shown in Figure 3.

According to the space coordinate transformation principle (Litvin, 1994), in the engagement process, matrix $M_{s s^{\prime}}$ represents the coordinate transformation from s' to $\mathrm{s}$ and is expressed as:

$$
M_{s s^{\prime}}=\left[\begin{array}{cccc}
\cos \theta_{1} & \sin \theta_{1} & 0 & 0 \\
-\sin \theta_{1} & \cos \theta_{1} & 0 & 0 \\
0 & 0 & 1 & 0 \\
0 & 0 & 0 & 1
\end{array}\right]
$$

Matrix $M_{f s}$ represents the coordinate transformation from s to $\mathrm{f}$ and is expressed as:

$$
M_{f s}=\left[\begin{array}{cccc}
1 & 0 & 0 & -r(0) \\
0 & 1 & 0 & 0 \\
0 & 0 & 1 & R \\
0 & 0 & 0 & 1
\end{array}\right]
$$

Matrix $M_{f^{\prime} f}$ represents the coordinate transformation from $\mathrm{f}$ to $\mathrm{f}^{\prime}$ and is expressed as:

$$
M_{f^{\prime} f}=\left[\begin{array}{cccc}
1 & 0 & 0 & 0 \\
0 & \cos \theta_{2} & \sin \theta_{2} & 0 \\
0 & -\sin \theta_{2} & \cos \theta_{2} & 0 \\
0 & 0 & 0 & 1
\end{array}\right]
$$

So the transformation matrix from $s^{\prime}$ to $f^{\prime}$ can be derived as:

$$
\begin{aligned}
& M_{f^{\prime} s^{\prime}}=M_{f f^{\prime}} M_{f s} M_{s s^{\prime}} \\
& =\left[\begin{array}{cccc}
\cos \theta_{1} & \sin \theta_{1} & 0 & -r(0) \\
-\cos \theta_{2} \sin \theta_{1} & \cos \theta_{1} \cos \theta_{2} & \sin \theta_{2} & R \sin \theta_{2} \\
\sin \theta_{1} \sin \theta_{2} & -\cos \theta_{1} \sin \theta_{2} & \cos \theta_{2} & R \cos \theta_{2} \\
0 & 0 & 0 & 1
\end{array}\right]
\end{aligned}
$$

The tooth surface equation of the face gear can be acquired by transforming the cutter profile from $s^{\prime}$ to $f^{\prime}$ as follows:

$$
\begin{aligned}
& \overrightarrow{\boldsymbol{r}_{2}}\left(u_{\mathrm{k}}, \theta_{\mathrm{k}}\right)=M_{f^{\prime} s} \overrightarrow{\boldsymbol{r}_{0}}\left(u_{\mathrm{k}}, \theta_{\mathrm{k}}\right) \\
& \overrightarrow{\boldsymbol{n}_{2}}=L_{f^{\prime} s} \overrightarrow{\boldsymbol{n}_{0}}=L_{f^{\prime} s} \frac{\frac{\partial \overrightarrow{\boldsymbol{r}_{0}}}{\partial \theta_{k}} \times \frac{\partial \overrightarrow{\boldsymbol{r}_{0}}}{\partial u_{k}}}{\left|\frac{\partial \overrightarrow{\boldsymbol{r}_{\mathrm{k}}}}{\partial \theta_{k}} \times \frac{\partial \overrightarrow{\boldsymbol{r}_{\mathrm{k}}}}{\partial u_{k}}\right|}
\end{aligned}
$$

Where $L_{f^{\prime} s^{\prime}}$ is the 3 rd order principal minor of $M_{f^{\prime} s^{\prime}}$.

In coordinate $O_{f^{\prime}}$, the equation of relative velocity ${\overrightarrow{f_{f}^{\prime} s^{\prime}}}^{\left(f^{\prime}\right)}$ can be expressed as:

$\overrightarrow{\boldsymbol{v}_{f^{\prime} s^{\prime}}}\left(f^{\prime}\right)=\left(\overrightarrow{\theta_{1}}-\overrightarrow{\theta_{2}}\right) \times M_{f^{\prime} \mathrm{s}^{\prime}} \overrightarrow{\boldsymbol{r}_{k}}$

According to gear meshing theory ${ }^{(15)}$, the engagement equation can be expressed as:

$\overrightarrow{\boldsymbol{n}_{2}} \cdot \overrightarrow{\boldsymbol{v}_{f s^{\prime}}}\left(f^{\prime}\right)=f\left(u_{\mathrm{k}}, \theta_{\mathrm{k}}, \theta_{2}\right)=0$

According to equation (7), the vector expression of tooth surface of the face gear can be deduced as: 


$$
\overrightarrow{\boldsymbol{r}_{2}}=\overrightarrow{\boldsymbol{r}_{2}}\left(\theta_{k}, \theta_{2}\right)
$$

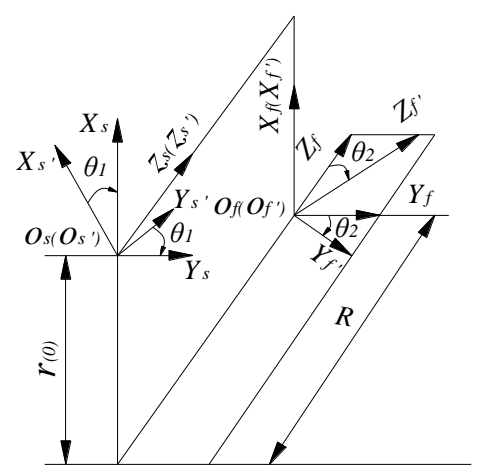

Fig. 3 The machining coordinate of the face gear

\subsection{Fillet Surface}

The design of the fillet surface can determine whether the tooth will undercut. Each tooth of the face gear is different, so is each fillet surface. So the parametric equation should be built to analyze the fillet surface. There are rounded corners in addendum angles of the cutter. The radius of the rounded corner is $\rho$, as shown in Figure 4. And the fillet surface is formed by the addendum angle of the cutter. The coordinate of the center $\mathrm{C}$ of the cutter addendum angle can be expressed as $\left(x_{c}, y_{c}\right)$. So the parametric equation of the cutter addendum angle is:

$$
\overrightarrow{r_{R}}=\left[\begin{array}{c}
x_{c}-\rho \cos \theta_{3} \\
y_{c}+\rho \sin \theta_{3} \\
u_{\mathrm{k}}
\end{array}\right]
$$

In coordinate a, the unit normal vector of the cutter addendum angle can be expressed as:

$$
\overrightarrow{\boldsymbol{n}_{\mathrm{R}}}=\left[\begin{array}{c}
-\cos \theta_{3} \\
\sin \theta_{3} \\
0
\end{array}\right]
$$

The relative velocity between the surface of the cutter addendum angle $\sum_{4}$ and the surface of the face gear $\sum_{3}$ in coordinate s can be expressed as:

$$
\overrightarrow{\boldsymbol{v}_{43}}(s)=\left(\overrightarrow{\theta_{1}}-\overrightarrow{\theta_{2}}\right) \times M_{s s} \overrightarrow{\boldsymbol{r}_{R}}
$$

Based on the space coordinate transformation principle, the unit normal vector of cutter addendum angle in coordinate s can be expressed as:

$$
\overrightarrow{\boldsymbol{N}_{\mathrm{R}}}(\mathrm{s})=L_{s s}, \overrightarrow{\boldsymbol{n}_{\mathrm{R}}}
$$

Where, $L_{s s^{\prime}}$ is the $3 \mathrm{rd}$ order principal minor of $M_{s s^{\prime}}$.

So the parametric equation of the fillet surface of the face gear is:

$$
\left\{\begin{array}{l}
\overrightarrow{\boldsymbol{r}_{4}}\left(u_{k}, \theta_{3}, \theta_{1}\right)=M_{f^{\prime} s^{\prime}} \overrightarrow{\boldsymbol{r}_{R}} \\
f\left(u_{k}, \theta_{3}, \theta_{1}\right)={\overrightarrow{\boldsymbol{N}_{R}}}^{(s)} \cdot{\overrightarrow{\boldsymbol{v}_{43}}}^{(s)}=0
\end{array}\right.
$$

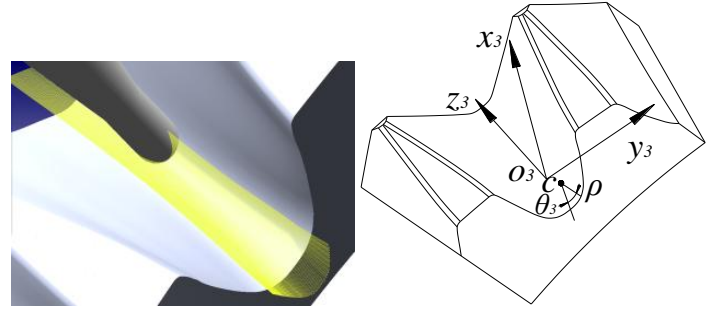

Fig. 4 Rounded corner in addendum angle 


\section{Processing method of the OVTR face gear 3.1 Processing principle of the OVTR face gear}

Three parameters ( $\theta_{m}, l_{k}$ and $h_{k}$, as shown in Fig. 5) are required for the rod cutter to process the OVTR face gear. $\theta_{m}$ is the inclination of the rod cutter resulting from its rotation around Z-axis, $l_{k}$ is the distance between the coordinate origin of the rod cutter and the coordinate origin of the face gear in $\mathrm{Z}$ direction, $h_{k}$ is the distance between the coordinate origin of the rod cutter and the coordinate origin of the face gear in $\mathrm{X}$ direction. $\theta_{m}, l_{k}$ and $h_{k}$ are functions of the independent variable $\theta_{2}$. Assuming that the surface equation of the face gear is $\overrightarrow{\boldsymbol{r}_{2}}\left(u_{k}, \theta_{k}\right)$, then the trajectory equation of the rob cutter can be obtained from the transformation matrix $O_{a}\left(\mathrm{X}_{a} Y_{a} Z_{a}\right)$ to $O_{e}\left(\mathrm{X}_{e} Y_{e} Z_{e}\right)$.

$$
\overrightarrow{\boldsymbol{r}}_{t}\left(u_{k}, \theta_{k}\right)=M_{e g}\left(\theta_{m}\right) M_{g i}\left(h_{k}, l_{k}\right) M_{i a}\left(\theta_{1}\right) \overrightarrow{\boldsymbol{r}}_{2}\left(u_{k}, \theta_{k}\right)=M_{e a}\left(\theta_{m}, h_{k}, l_{k} \theta_{1}\right) \overrightarrow{\boldsymbol{r}}_{2}\left(u_{k}, \theta_{k}\right)
$$

Where

$$
\begin{aligned}
& M_{e g}\left(\theta_{m}\right)=\left[\begin{array}{cccc}
\cos \theta_{m} & -\sin \theta_{m} & 0 & 0 \\
\sin \theta_{m} & \cos \theta_{m} & 0 & 0 \\
0 & 0 & 1 & 0 \\
0 & 0 & 0 & 1
\end{array}\right] \\
& M_{g i}\left(h_{k}, l_{k}\right)=\left[\begin{array}{cccc}
1 & 0 & 0 & h_{k} \\
0 & 1 & 0 & 0 \\
0 & 0 & 1 & l_{k} \\
0 & 0 & 0 & 1
\end{array}\right] \\
& M_{i a}\left(\theta_{1}\right)=\left[\begin{array}{ccccc}
1 & 0 & 0 & 0 \\
0 & \cos \theta_{2} & -\sin \theta_{2} & 0 \\
0 & \sin \theta_{2} & \cos \theta_{2} & 0 \\
0 & 0 & 0 & 1
\end{array}\right]
\end{aligned}
$$

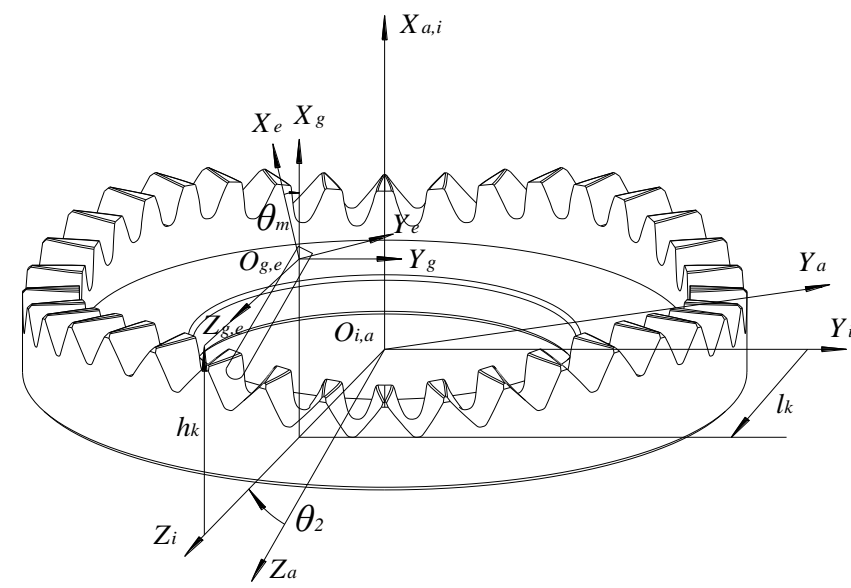

Fig. 5 Positional relationship between the cutter and the production-shaped gear

The five-axis $\mathrm{CNC}$ has five numerically closed-loop controlled axes: three rectilinear motions, $c_{x}, c_{y}, c_{z}$ and two rotational motions, $\psi_{a}, \psi_{c}$, as shown in Fig. 7. Figure 6 shows the processing principle of the face gear, Face gear tooling processing consists of two parts, one is the tool rotation around its own axis, the other is that tool tooth profile Converts to Production-shaped wheel, with the meshing movement with Face gear blank. $O_{c}$ is fixed at the center of Non-circular gear which is supposed to mesh with face gear. $O_{b}\left(\mathrm{X}_{b} Y_{b} Z_{b}\right)$ is obtained from $O_{a}\left(X_{a} Y_{a} Z_{a}\right)$ with angle $\psi_{a}$ of rotation around the axis of $\mathrm{X}$ axis. $O_{c}\left(\mathrm{X}_{c} Y_{c} Z_{c}\right)$ is obtained from $O_{b}\left(\mathrm{X}_{b} Y_{b} Z_{b}\right)$ with movement $K_{1}$ in $\mathrm{Y}$ direction, $C_{z}$ in $\mathrm{Z}$ direction, $C_{x}$ in $\mathrm{X}$ direction. $O_{d}\left(\mathrm{X}_{d} Y_{d} Z_{d}\right)$ is obtained from $O_{c}\left(\mathrm{X}_{c} Y_{c} Z_{c}\right)$ with angle $\psi_{b}$ of rotation around the axis of $\mathrm{Z}$ axis. $O_{e}\left(\mathrm{X}_{e} Y_{e} Z_{e}\right)$ is obtained from $O_{d}\left(\mathrm{X}_{d} Y_{d} Z_{d}\right)$ with movement $C_{y}$ in $\mathrm{Y}$ direction, $O_{e}\left(\mathrm{X}_{e} Y_{e} Z_{e}\right)$ is fixed at pitch curve and center of tooth width . 


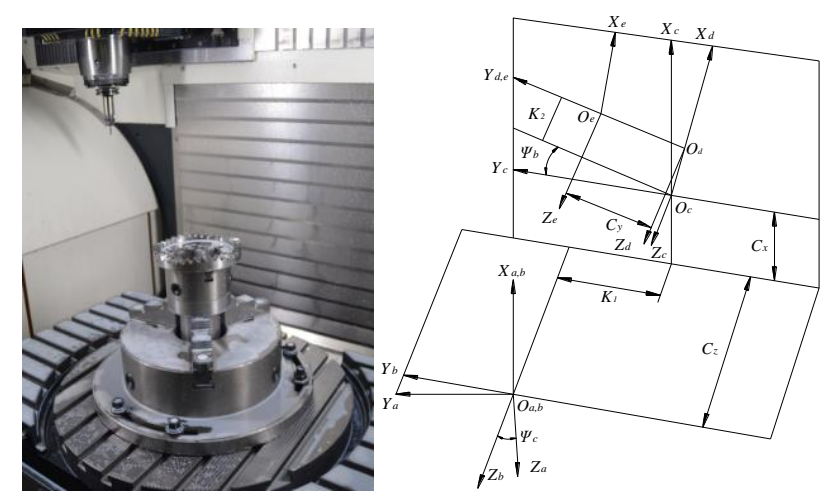

Fig. 6 Positional relationship between the cutter and Non-circular gear

Transforming Coordinate System $S_{e}$ of rob cutter to Coordinate System $S_{a}$ of face gear:

$\overrightarrow{\boldsymbol{r}_{2}^{(J)}}\left(u_{k}, \theta_{k}\right)=M_{a b}^{(J)}\left(\psi_{c}\right) M_{b c}^{(J)}\left(c_{x}, c_{z}\right) M_{c d}^{(J)}\left(\psi_{b}\right) M_{d e}^{(J)}\left(c_{y}\right) \overrightarrow{\boldsymbol{r}_{t}^{(J)}}\left(u_{k}, \theta_{k}\right)=M_{a e}^{(J)}\left(\psi_{b}, \psi_{c} c_{x}, c_{y}, c_{z}\right) \overrightarrow{\boldsymbol{r}_{t}^{(J)}}\left(u_{k}, \theta_{k}\right)$

Where

$$
\begin{aligned}
& M_{a b}^{(J)}\left(\psi_{c}\right)=\left[\begin{array}{cccc}
1 & 0 & 0 & 0 \\
0 & \cos \psi_{c} & \sin \psi_{c} & 0 \\
0 & -\sin \psi_{c} & \cos \psi_{c} & 0 \\
0 & 0 & 0 & 1
\end{array}\right] \\
& M_{b c}^{(J)}\left(c_{x}, c_{z}\right)=\left[\begin{array}{cccc}
1 & 0 & 0 & -c_{x} \\
0 & 1 & 0 & k_{1} \\
0 & 0 & 1 & c_{z} \\
0 & 0 & 0 & 1
\end{array}\right] \\
& M_{c d}^{(J)}\left(\psi_{a}\right)=\left[\begin{array}{cccc}
\cos \psi_{b} & -\sin \psi_{b} & 0 & -k_{2} \cos \psi_{b} \\
\sin \psi_{b} & \cos \psi_{b} & 0 & k_{2} \sin \psi_{b} \\
0 & 0 & 1 & 0 \\
0 & 0 & 0 & 1
\end{array}\right] \\
& M_{d e}^{(J)}\left(c_{y}\right)=\left[\begin{array}{cccc}
1 & 0 & 0 & 0 \\
0 & 1 & 0 & -c_{y} \\
0 & 0 & 1 & 0 \\
0 & 0 & 0 & 1
\end{array}\right] \\
& M_{a e}=M_{a b} M_{b c} M_{c d} M_{d e}= \\
& {\left[\begin{array}{cccc}
\cos \psi_{b} & -\sin \psi_{b} & 0 & -c_{x}-c_{y} \sin \psi_{b} \\
\cos \psi_{c} \sin \psi_{b} & \cos \psi_{b} \cos \psi_{c} & -\sin \psi_{c} & k_{1} \cos \psi_{c}+c_{z} \sin \psi_{c}+c_{y} \cos \psi_{b} \cos \psi_{c} \\
\sin \psi_{b} \sin \psi_{c} & \cos \psi_{b} \sin \psi_{c} & \cos \psi_{c} & k_{1} \sin \psi_{c}-c_{z} \cos \psi_{c}+c_{y} \cos \psi_{b} \sin \psi_{c} \\
0 & 0 & 0 & 1
\end{array}\right]}
\end{aligned}
$$

$M_{a e}$ is transformation matrix from $S_{e}$ to $S_{a}, M_{a b}$ is transformation matrix from $\mathrm{Ob}$ to $O_{a}, M_{b c}$ is transformation matrix from $O_{c}$ to $O_{b}, M_{c d}$ is transformation matrix from $O_{d}$ to $O_{c}, M_{d e}$ is transformation matrix from $O_{e}$ to $O_{d}$.

The relative spatial position of the wheel axis with respect to the work gear axis should be the same whether the work gear is ground on a universal or a CNC machine. Therefore, comparing Eq. (16) with Eq. (25) satisfies the following relation:

$$
M_{a e}^{(J)}\left(\psi_{b}, \psi_{c}, c_{x}, c_{y}, c_{z}\right)=M_{a e}\left(\theta_{m}, h_{k}, l_{k}, \theta_{1}\right)=M_{e a}^{-1}\left(\theta_{m}, h_{k}, l_{k}, \theta_{1}\right)
$$

Assuming that the rotational position of the work gear on the universal profile grinding machine is the same as on the $\mathrm{CNC}$ machine, the angle positions of the CNC machine can be derived as follows through comparison with the $3 \times 3$ 
rotation matrices in Eq. (26):

$$
\left\{\begin{array}{l}
\psi_{c}\left(\theta_{2}\right)=\theta_{2} \\
\psi_{b}\left(\theta_{2}\right)=\theta_{m}
\end{array}\right.
$$

With the above formula, the expressions for the numerical translational axis are:

$$
\left\{\begin{array}{l}
c_{x}\left(\theta_{2}\right)=h_{k}\left(\theta_{2}\right) \cos \left(\theta_{m}\right) / \cos \left(\theta_{2}\right)+k_{1} \tan \left(\theta_{2}\right)-k_{2} \cos \left(\theta_{2}\right)+k_{2} \sin \left(\theta_{2}\right) \tan \left(\theta_{2}\right) \\
c_{y}\left(\theta_{2}\right)=h_{k}\left(\theta_{2}\right) \sin \theta_{m}+k_{1} \cos \theta_{2}+\sin \theta_{2}\left(h_{k}\left(\theta_{2}\right) \cos \left(\theta_{m}\right) / \cos \left(\theta_{2}\right)+k_{1} \tan \left(\theta_{2}\right)-k_{2} \cos \left(\theta_{2}\right)+k_{2} \sin \left(\theta_{2}\right) \tan \left(\theta_{2}\right)\right) \\
+2 k_{2} \sin \left(\theta_{2}\right) \cos \left(\theta_{2}\right) \\
c_{z}\left(\theta_{2}\right)=l_{k}\left(\theta_{2}\right)
\end{array}\right.
$$

Processing face gear with generating method, numerical control axes movement locations are shown in table 1.

Table 1 Numerical control axes movement locations of gear machine with five axes CNC.

\begin{tabular}{c|c|c|c|c}
\hline \hline $\mathrm{X}$ axis & Y axis & $\mathrm{Z}$ axis & B axis & C axis \\
\hline-83.684 & -8.792 & 5.713 & -20.000 & 11.828 \\
\hline-82.813 & -8.676 & 5.690 & -19.974 & 11.810 \\
\hline-82.569 & -8.642 & 5.689 & -19.959 & 11.805 \\
\hline-82.782 & -8.537 & 5.706 & -19.954 & 11.812 \\
\hline 81.3809 & -8.4804 & 5.708 & -19.959 & 11.815 \\
\hline-80.995 & -8.436 & 5.732 & -19.974 & 11.818 \\
\hline-80.207 & -8.342 & 5.753 & -20.000 & 11.825 \\
\hline$\ldots$ & $\ldots$ & $\ldots$ & $\ldots$ & $\ldots$ \\
\hline 81.289 & -20.370 & 7.798 & -19.999 & 19.898 \\
\hline-82.069 & -20.537 & 7.817 & -19.973 & 19.879 \\
\hline-82.459 & -20.620 & 7.828 & -19.957 & 19.869 \\
\hline
\end{tabular}

\subsection{CNC machining model of OVTR face gear}

General face gears can be processed by three-axis CNC, because the teeth on these gears are the same. However, the teeth on an OVTR face gear are totally different, so at least four-axis CNC is required. This research report discusses the processing of the OVTR face gear using a five-axis CNC machine. The CNC machine model is shown in Fig. 7. All the required motions for the processing are achieved by six CNC axes, including three translational axes, two rotation axes, and a high speed shaft. Essentially, only the three translational axes and the two rotational axes are coordinated controlled, where as the high speed shaft (Axis 6) is just responsible for cutting. However, all the three rotary axes were engaged in the machining.

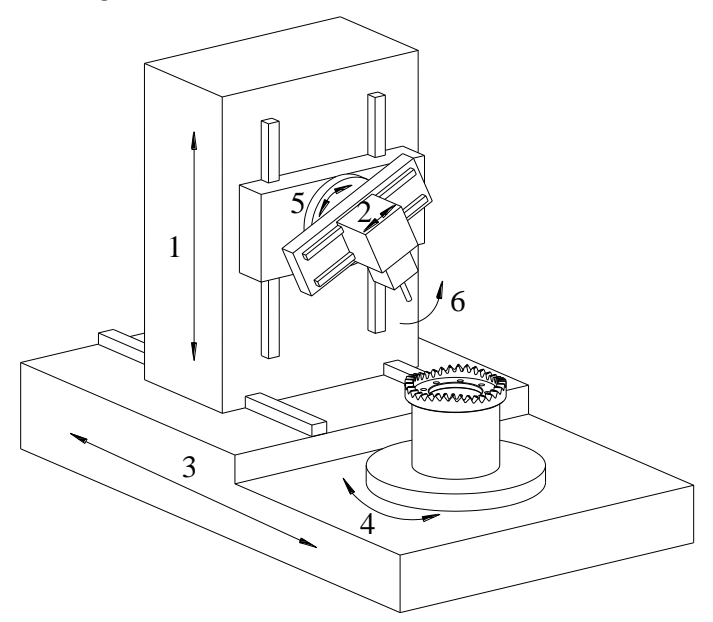
1. Vertical stroke slide $\left(\mathrm{X}, C_{x}\right)$
4. Work-piece spindle $\left(C, \psi_{c}\right)$
2. Wheel axial slide $\left(\mathrm{Y}, C_{y}\right)$
5. Wheel swivel axis $\left(B, \psi_{b}\right)$ 


\section{Radial slide $\left(\mathrm{Z}, C_{z}\right) \quad$ 6. Cutter spindle (A)}

Fig. 7 Five-axis CNC machine model

This paper presents a five-axis CNC machining method of the orthogonal variable ratio face gear. According to the gear engagement theory, instantaneous contact line will be generated at every moment, when the production-shaped gear is engaged with the face gear. This contact line has a cutting effect on the face gear blank, and finally generates the orthogonal variable ratio face gear, as shown in Fig. 8. This method is used in the processing of the orthogonal variable ratio face gear, which means the cutter moves along the contact line during the cutting process.
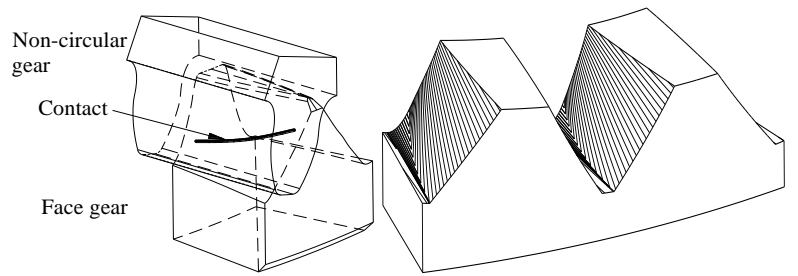

Fig.8 instantaneous contact line of face gear

The contact line, which is generated by the engagement of the cutter tooth surface $\sum_{1}$ and the non-circular tooth surface $\sum_{2}$, is $L_{2}$. The non-circular tooth surface $\sum_{2}$ and the face gear tooth surface generate contact line $L_{1}$. The face gear is enveloped by cutter tooth surface, and the contact line is inclined compared with the tooth top line. Similarly, the non-circular gear is also enveloped by the cutter tooth surface, but the contact line is horizontal. So when the non-circular gear is engaged with the face gear, they are in point contact. The contact point is the intersection of $L_{1}$ and $L_{2}$, as shown in Fig.9 ( $r_{f}$ is distance between pitch curve point and original point, $n_{1} n_{2}$ is tooth surface normal vectors). Such contact method can reduce the sensitivity of the assembly error.

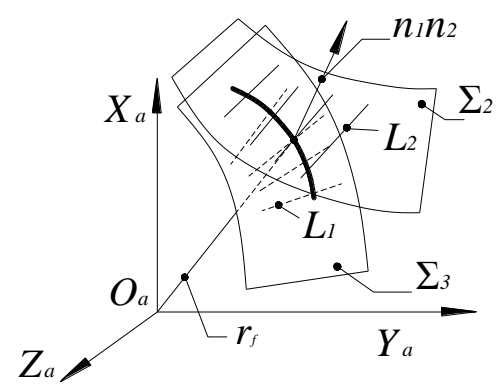

Fig. 9 Instantaneous contact line of a face gear

\section{Processing example}

Due to the complexity of the processing, only the most typical oval face gear was processed at this time. The non-circular gear had a small number of teeth in order to control the size of face gear. The specific geometry parameters are shown in table 2.

Table 2 Geometry parameters of the OVTR face gear dive.

\begin{tabular}{l|c}
\hline \multicolumn{1}{c|}{ Parameter name } & Value \\
\hline Number of teeth of Non-circular gear $z_{1}$ & 18 \\
\hline Number of teeth of face gear $z_{2}$ & 36 \\
\hline Modulus $m(\mathrm{~mm})$ & 4 \\
\hline Order of Non-circular gear $n_{1}$ & 2 \\
\hline Order of face gear $n_{2}$ & 4 \\
\hline Eccentricity $k$ & 0.1 \\
\hline Addendum coefficient $h a^{*}$ & 1 \\
\hline Headspace coefficient $C^{*}$ & 0.25 \\
\hline Inner radius of the face gear $R_{1}(\mathrm{~mm})$ & 70 \\
\hline Outer radius of the face gear $R_{2}(\mathrm{~mm})$ & 83 \\
\hline Tooth width $(m m)$ & 13 \\
\hline
\end{tabular}


Processing steps included blank rough machining, cogging machining, tooth surface semi-finishing, fillet surface semi-finishing, tooth surface finish, and fillet surface finish, as shown in Fig. 10.

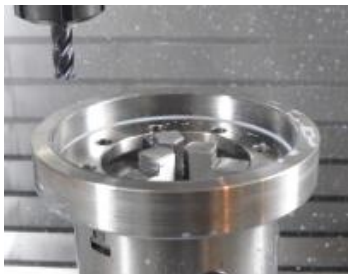

(a) Blank

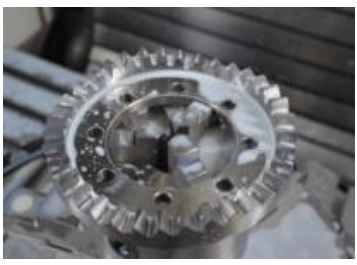

(d)Semi-finishing

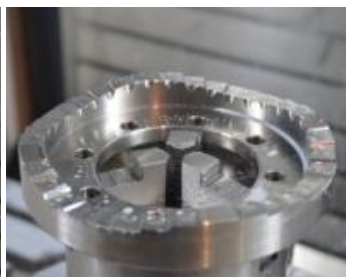

(b) Blank rough machining

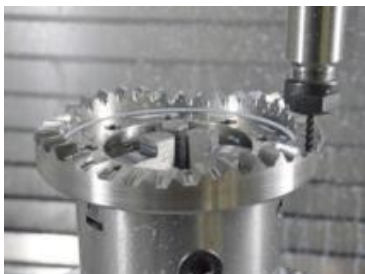

(c) Cogging machining

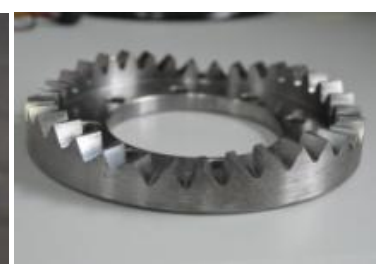

(f) End product

Fig. 10 Processing steps of OVTR face gear

It is necessary to measure the surface accuracy of the face gear after processing was completed. A CNC gear measuring center was employed in this measurement as shown in fig. 11. In order to avoid the calculation error caused by coordinate transformation in the post-processing of measurement data, the coordinate system of the tested workpiece was established before the measurement experiment according to the principle of the 321 (Wang and Zheng, 2004). The specific implementation procedures are as follows:

(1)More than three points were collected on the datum plane of the workpiece to determine the normal vector, which was regarded as the first axis direction of the workpiece coordinate system.

(2)More than two points were collected on the datum line (generally the axis of the hole or shaft) of the workpiece. If this straight line was not on the datum plane, the direction of projection on its datum plane was regarded as the second axis direction of the workpiece coordinate system.

(3)A datum point on the test workpiece was collected as the origin of the workpiece coordinate system.

Finally, the direction vector of the third axis can be obtained by doing cross product of the direction vectors of the first and the second axis. At this point, the workpiece coordinate system can be completely determined.

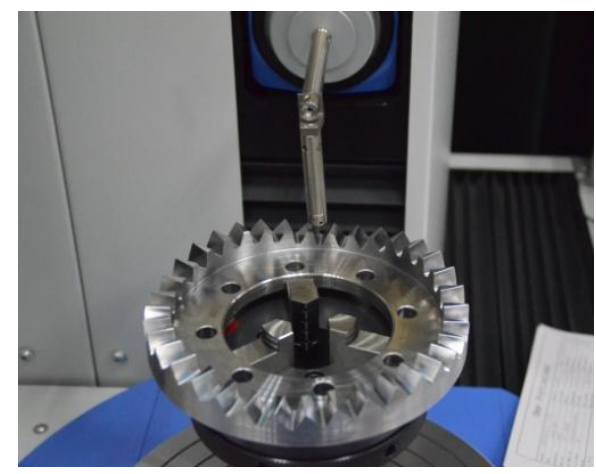

Fig. 11 CNC gear measuring center

Since this is a new type of gear, there is no model of such gear in the CNC Measuring Center. Thus error processi ng cannot be conducted in the measuring system. The only approach is to export the measuring data and to process erro rs in 3D software basing on the 3D model of the gear. As each cycle of the face gear has a peak and a trough, they are representative for the face gear. A peak tooth and a trough tooth were selected to conduct the error evaluation. Both the left and the right teeth surfaces were divided into 5x5 grids, and error in the direction normal to the tooth surface was obtained, as shown in Fig.12. 


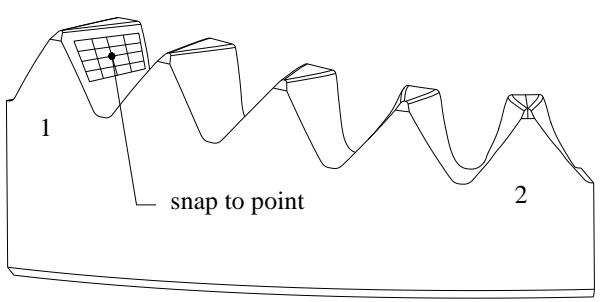

(a) Selected tooth number

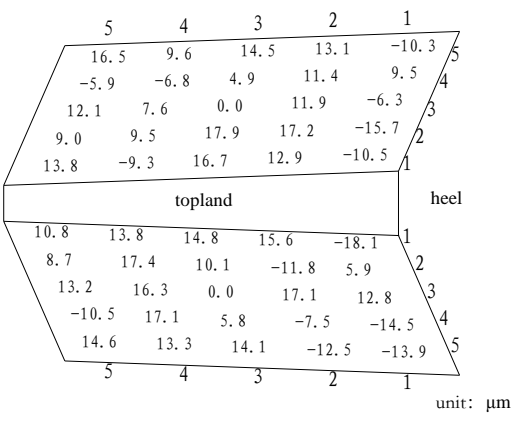

(b) Tooth surface 1

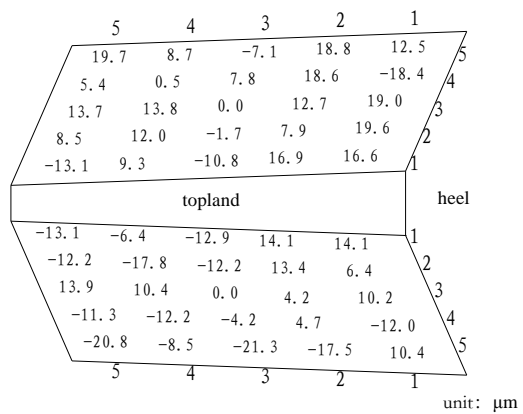

(c) Tooth surface 2

Fig. 12 Error in the direction normal to the tooth surface

It can be seen from Fig. 12 that the maximum error of tooth 1 is $-18.1 \mu \mathrm{m}$, the maximum error of tooth 2 is $19.7 \mu \mathrm{m}$.。 It was confirmed that these samples were manufactured with high accuracy.

After finishing processing and heat treatment of the face gear, rolling experiment was required in order to verify whether the real contact line matches the theoretical one. Fig. 13 shows the rolling experiment for the face gear on a universal rolling test machine.

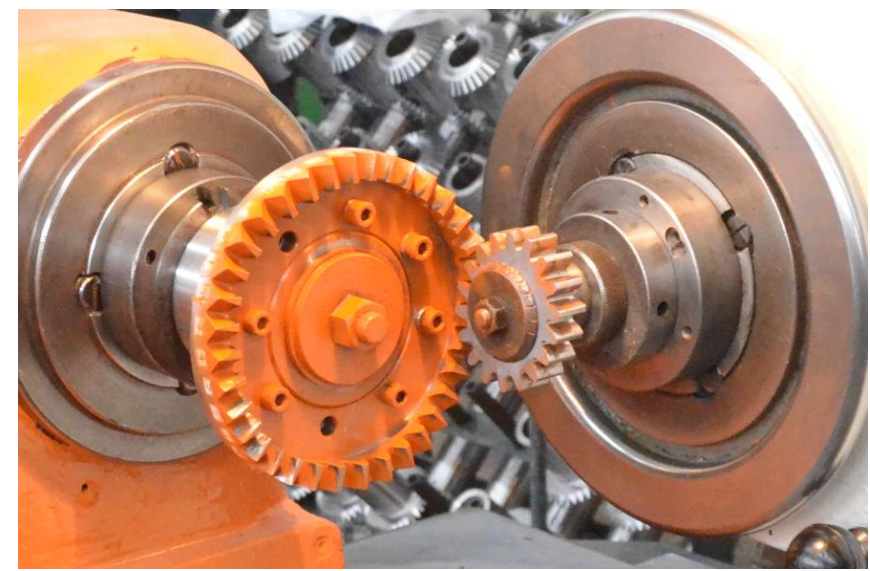

Fig. 13 Face gear testing on roll

After assembly and adjustment, the testing on roll indicated that the face gear processed by the five-axis CNC exhibited a good contact trajectory and smooth engagement. Since the face gear has periodicity, five teeth on one period were chosen and their contact pattern was recorded and measured. The percentage of contact pattern along the radial and longitudinal direction could be obtained. The results are shown in Fig. 3. The percentage of contact along the radial direction was larger than that along the longitudinal direction.

Table 3 Evaluation of contact pattern.

\begin{tabular}{|c|c|c|c|c|}
\hline $\begin{array}{l}\text { order } \\
\text { number }\end{array}$ & $\begin{array}{l}\text { contact } \\
\text { pattern }\end{array}$ & $\begin{array}{l}\text { Evaluation method of contact } \\
\text { pattern }\end{array}$ & $\begin{array}{l}\text { Percentage of radial } \\
\text { direction } \\
\eta=\left(b^{\prime \prime}-c\right) / b^{\prime} \times 100 \%\end{array}$ & $\begin{array}{l}\text { Percentage of } \\
\text { longitudinal } \\
\text { direction } \\
\zeta=h^{\prime \prime} / h^{\prime} \times 100 \%\end{array}$ \\
\hline 1 & & $b^{\prime}$ & 98.2 & 31.5 \\
\hline 2 & & U & 81.6 & 48.8 \\
\hline 3 & & 1 & 56.0 & 13.5 \\
\hline 4 & & & 92.4 & 69.3 \\
\hline 5 & & & 99.1 & 68.4 \\
\hline
\end{tabular}




\section{Conclusions}

(1) The tooth surface equation of the face gear was obtained by coordinate transformation of the cutter tooth profile equation, which ensured the correct engagement of the face gear pair.

(2) The tooth root angle equation of the face gear was derived from the cutter addendum angle equation. The parametric equation of the fillet surface on the OVTR face gear was obtained.

(3) The CNC machining model of the OVTR face gear was established to analyze the movement relation between the translational axes xyz and the rotation axes AB. Mathematical expressions of the five axes on CNC were obtained. A method to process OVTR face gear along the contact line was proposed. The machining of the OVTR face gear was achieved by a five-axis CNC. Rolling experiment and tooth surface measurement indicated that the machined OVTR face gear pair exhibited good engagement and high accuracy, and verified the design of the OVTR face gear and its machining method using a five-axis CNC machine.

\section{Acknowledgements}

The authors would like to appreciate their supports from the National Natural Science Foundation of China (51275537).

\section{References}

Frackowiak, P., Ptaszynski, W. and Stoic, A., New geometry and technology of face-gear forming with circle line of teeth on CNC milling machine, Metalurgija, Vol.51, No.1 (2012), pp.109-112.

George, B., Procedure for tooth contact analysis of a face gear meshing with a spur gear using finite element analysis(2002), pp. 2-5, NASA.

Gunbara, H., Geometrical design of face gear, Transactions of the Japan Society of Mechanical Engineers, Series C, Vol. 73, No.726(2007), pp.227-231.

Ishii, Harumi, Nagata and Shigeyoshi, Tooth cutting method of face gear by using CNC-hobbing machine, American Society of Mechanical Engineers, Design Engineering Division, Vol.43, No.1 (1992), pp. 209-214.

Litvin, F., Zhang, Y. and Wang J., Design and geometry of face gear drives, Journal of Mechanical Design, Vol.144, No.4 (1992), pp. 642-647.

Litvin, F., Gear Geometry and Applied Theory (1994), Prentice-Hall.

Litvin, F., Alfonso, F., Claudio, Z. and Matteo P., Design, generation, and stress analysis of two versions of geometry of face-gear drives, Mechanism and Machine Theory, Vol.37, No.10 (2002), pp.1179-1211.

Litvin, F., Ignacio, G., Alfonso, F., Daniele, V., Bruce, D. and David, B., Design, generation and stress analysis of face-gear drive with helical pinion, Computer Methods in Applied Mechanics and Engineering, Vol.194, No.36-38 (2005), pp.3870-3901.

Oshima, F., Yoshino, H., Study on high reduction face gears (1st Report, Meshing Analysis), Transactions of the Japan Society of Mechanical Engineers, Series C, Vol.72, No.720(2006), pp.336-342.

Oshima, F., Yoshino, H., Study on high reduction face gears (3st Report, Proposal of Simplified Design Method), Transactions of the Japan Society of Mechanical Engineers, Series C, Vol.73, No.732(2007), pp.201-206.

Oshima, F., Yoshino, H., Contact pattern and running performance of face gears with high gear ratio, The JSMA Symposium on Motion and power Transmission 2007, No.07-15(2007), pp.167-168.

Oshima, F., Yoshino, H. and Nagata E., A study on high reduction face gears (2ndReport, Cutting of Face Gear), Transactions of the Japan Society of Mechanical Engineers, Series C, Vol. 75, No.758(2009), pp.212-217.

Ohshima, Fumihiro, Yoshino, Hidehiro, Nagata and Eiri, A study on high reduction face gears. Hen/Transactions of the Japan Society of Mechanical Engineers, Part C, Vol.75, No.758 (2009), pp. 2816-2821.

Tetsuo, I. and Syuhei, K., Derivation of path of contact and tooth flank modification by minimizing transmission error on face gear, Journal of Advanced Mechanical Design, Systems, and Manufacturing, Vol.6, No.1(2012), pp.15-22.

Wang, Y. P. and Zheng Y. L., Creation method of coordinate system in 3D measuring software system, Industrial 
Lin, Fan, Wang, Cao and Cai, Journal of Advanced Mechanical Design, Systems, and Manufacturing, Vol.8, No.3 (2014)

Measurement, Vol.6, No.14 (2004), pp. 27-30(in Chinese). 